\title{
A Familial Adenomatous Polyposis (FAP) patient education conference and its impact on patients and families
}

\author{
Devki S Saraiya*, Thuy M Vu, Robert L Askew, Susan K Peterson, Miguel A Rodriguez-Bigas, Patrick M Lynch \\ From 13th Annual Meeting of the Collaborative Group of the Americas on Inherited Colorectal Cancer \\ Honolulu, Hawaii, USA. 16-17 October 2009
}

\section{Background}

Individuals with familial adenomatous polyposis (FAP) require increased lifelong surveillance due to the high risk of colorectal cancer and extracolonic features. Despite the existence of well-established surveillance guidelines, studies have shown that lack of patient knowledge is a major hurdle to adherence. Patient education conferences represent an avenue for patients to obtain disease-specific information directly from experts. There is a paucity of data addressing the educational needs and characteristics of individuals who attend such conferences and the impact on their FAP-related knowledge.

\section{Methods}

Individuals with FAP identified through the institution's FAP registry and their family members were invited to attend an educational conference. Adult attendees were provided IRB approved baseline and follow-up surveys as part of their conference packets. The paired surveys were matched through the use of a unique survey identifier and contained items pertaining to demographic and clinical history, FAP knowledge, and effectiveness of the conference and presenters.

\section{Results}

Of the 50 conference attendees, 35 (70\%) completed baseline assessments, and 32 (64\%) completed the postconference counterpart. Respondents' median age was 51 (range: 2472 ), and 66\% were female. Nineteen (54\%) indicated that they had FAP, of which 12 (63\%) had undergone colorectal surgery. Fundic gland polyps, duodenal polyps, and desmoid tumors were present in 9 (47\%), 11 (58\%), and 3 (16\%) affected participants, respectively. Hepatoblastoma, duodenal cancer, and osteomas were reported in 1 individual each. Regarding surveillance, $14(74 \%)$ and $13(68 \%)$ of the affected respondents received upper and lower GI surveillance at least once every 3 years, respectively. Participants indicated that among healthcare professionals, their primary sources of information on FAP were primary care physicians $(n=15)$, surgeons $(n=12)$ and/or genetic counselors $(n=13)$. Additional sources of information included internet based resources $(n=32)$, print materials $(n=22)$, and/or other individuals familiar with FAP $(n=27)$. Respondents scored on average 69\% correct on a 14-item measure of FAP-related knowledge prior to the conference; post-conference responses showed a statistically significant increase in mean scores (mean $=77 \%$, $\mathrm{p}<0.05)$. Thirty-one of post-conference respondents (97\%) agreed or strongly agreed with items affirming conference effectiveness. Most attendees stated that the FAP conference provided them with information critical to informed medical decision making. All respondents stated a desire to attend future FAP conferences.

\section{Conclusions}

Conference attendees represented the wide clinical spectrum of FAP, with most adhering to high-risk surveillance guidelines. While the majority of participants

* Correspondence: dssaraiya@mdanderson.org

University of Texas M. D. Anderson Cancer Center, Houston, Texas 77030, USA 
obtained their FAP-related information from the internet, they may benefit from improved educational efforts that encourage active participation in their own maintenance and treatment of FAP. Future conferences should be targeted to meet the broad range of patient interest and knowledge in FAP-related topics.

Published: 25 May 2010

doi:10.1186/1897-4287-8-S1-P20

Cite this article as: Saraiya et al: A Familial Adenomatous Polyposis (FAP) patient education conference and its impact on patients and families. Hereditary Cancer in Clinical Practice 2010 8(Suppl 1):P20.

Submit your next manuscript to BioMed Central and take full advantage of:

- Convenient online submission

- Thorough peer review

- No space constraints or color figure charges

- Immediate publication on acceptance

- Inclusion in PubMed, CAS, Scopus and Google Scholar

- Research which is freely available for redistribution

Submit your manuscript at www.biomedcentral.com/submit 